\title{
DISCUSSION
}

\section{A novel formula for the prediction of swelling pressure of compacted expansive soils}

\author{
H. ELSAIDY* ${ }^{\star}$, W. M. YAN ${ }^{\star}+$, M. J. PENDER* ${ }^{*}$ A. SOLTANI§ and B. C. O’KELLY\|
}

ICE Publishing: all rights reserved

\section{CONTRIBUTION BY SOLTANI AND O'KELLY}

Recently, Elsaidy et al. (2019) have proposed a novel empirical model - that is, equation (6) in the original manuscript - for the prediction of the one-dimensional swelling pressure of compacted expansive soils. A total of four expansive soils, designated as soils A, B, C and D in the original manuscript, were examined. According to Table 1 of the original manuscript, the four soils have different degrees of expansivity, ranging from non-expansive to highly expansive. Model development and its calibration were performed using soils $\mathrm{A}$ and $\mathrm{B}$, while model validation involved the use of soils $\mathrm{C}$ and $\mathrm{D}$, and two additional expansive soils (or datasets) compiled from the literature (i.e. BAS and E\&G, as outlined in Appendix B of the original manuscript). The proposed model makes use of the free swell index (FSI) and initial compaction/moulding state parameters of the soil, namely initial water content and dry density. The study under discussion is a welcome addition to the existing literature.

Towards addressing some potential issues associated with the investigation of Elsaidy et al. (2019), the contributors would like to elaborate on reported shortcomings associated with the FSI parameter, its correlation with the liquid limit (LL), and the authors' assumed linear relationships between the FSI and the fitting parameters $(\alpha$ and $\beta)$ of their proposed model (i.e. equations (5a) and (5b) in the original manuscript).

\section{Correlation of FSI with LL}

Referring to the table given in Appendix B of the original manuscript, the FSI for the datasets BAS and E\&G was estimated by means of the LL. Figure 5 illustrates the variations of FSI against LL for 78 soil samples gathered from the literature (Prakash \& Sridharan, 2004; Rao et al., 2004), along with soils A-D examined by the authors (Elsaidy et al., 2019). As is evident from this figure, the data points are significantly scattered, thus indicating that the FSI generally poorly correlates with the LL. The same

*Department of Civil and Environmental Engineering, The University of Auckland, Auckland, New Zealand.

$\dagger$ Jacobs New Zealand Limited, Auckland, New Zealand.

$\triangle$ AECOM Asia Company Limited, Hong Kong.

$\S$ School of Engineering, IT and Physical Sciences, Federation

University, Churchill, VIC, Australia

(Orcid:0000-0002-0483-7487).

||Department of Civil, Structural and Environmental Engineering, Trinity College Dublin, Dublin, Dublin 2, Ireland

(Orcid:0000-0002-1343-4428). observation is made when one considers the data subset, confined to the narrow FSI range of 0 to $50 \%$, from the Prakash \& Sridharan (2004) investigation. Furthermore, it can be observed that soils having the same LL magnitude can have significantly different FSI values (and vice versa). Accordingly, it is suggested that the authors' adopted FSI from the LL approach using the correlations shown in Fig. 1 of the original manuscript, at best, may only provide a rough approximation of the FSI for the datasets BAS and E\&G. Hence, the predicted swelling pressures for the datasets BAS and $E \& G$ presented by the authors may be associated with some degree of uncertainty. For the model validation, the contributors would like to recommend the data published in Rao et al. (2004) - their study consists of ten expansive soils with measured FSI values, each tested for swelling pressure at varying initial placement conditions.

\section{FSI and soil expansivity assessments}

The FSI, as used by the authors in their proposed model, is defined as follows:

$$
\operatorname{FSI}(\%)=\frac{V_{\mathrm{d}}-V_{\mathrm{k}}}{V_{\mathrm{k}}} \times 100
$$

where $V_{\mathrm{d}}$ and $V_{\mathrm{k}}$ are the equilibrium sediment volumes of $10 \mathrm{~g}$ oven-dried soil, passing the $425-\mu \mathrm{m}$ sieve size, when placed in distilled water and kerosene, respectively.

It is well accepted that the equilibrium sediment volume of kaolinite-rich soils in non-polar liquids, in this case kerosene, can be greater than that obtained in distilled water, meaning that $V_{\mathrm{k}}>V_{\mathrm{d}}$ (Sridharan et al., 1985; Prakash \& Sridharan, 2004; Nagaraj \& Suresh, 2019). Sridharan \& Prakash (1999) explained this behaviour stating that 'the equilibrium sediment volume of kaolinitic soil is mainly due to flocculation, while that of montmorillonitic soil is primarily due to diffuse double-layer repulsive forces'. In such cases, equation (1) will produce negative and hence meaningless FSI values (e.g. see Fig. 5), despite the fact that such soils may possess a notable swelling pressure potential. For the same reason, the FSI, even when positive, may underestimate the swelling potential (or expansivity) of montmorillonitic soils, particularly if the soils concerned contain a notable amount of kaolinite (Sridharan \& Prakash, 2000). Furthermore, although the FSI claims to be a quantitative measure of, and hence a means of classification for, clay mineralogy, to the knowledge of contributors, no such classification has been established based on the FSI.

To cope with the mentioned shortcomings associated with the FSI, Sridharan \& Prakash (2000) introduced the free swell ratio (FSR) that can be defined as $\mathrm{FSR}=V_{\mathrm{d}} / V_{\mathrm{k}}$. 


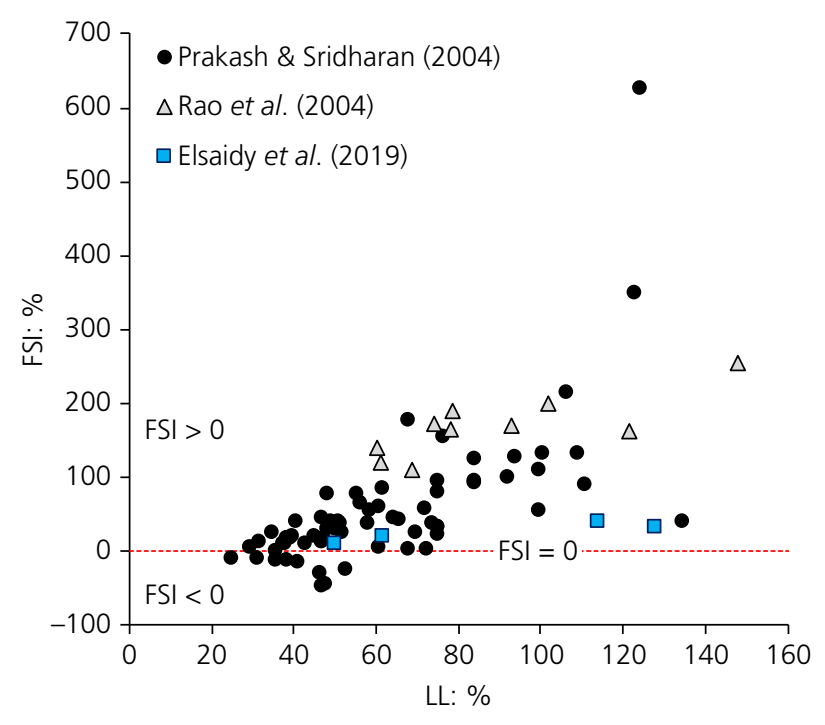

Fig. 5. Variations of FSI against LL for 78 soil samples gathered from the literature, along with soils A-D examined by the authors

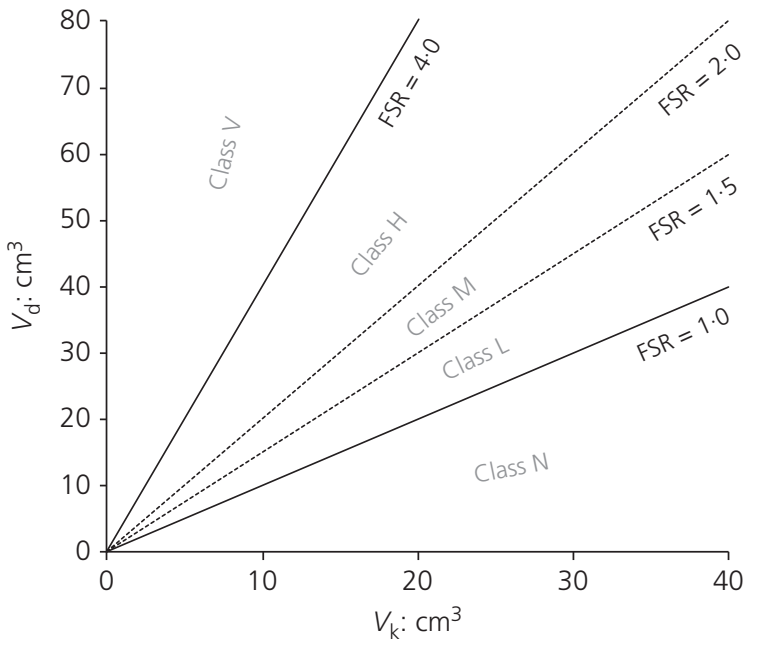

\begin{tabular}{|c|c|c|}
\hline $\mathrm{FSR}=V_{\mathrm{d}} / V_{\mathrm{k}}$ & Swelling potential & Dominant clay mineral \\
\hline$\leq 1.0$ & Negligible $(\mathrm{N})$ & Kaolinite \\
$1.0-1.5$ & Low $(\mathrm{L})$ & Kaolinite + montmorillonite \\
$1.5-2.0$ & Moderate $(\mathrm{M})$ & Montmorillonite \\
$2.0-4.0$ & High $(\mathrm{H})$ & Montmorillonite \\
$>4.0$ & Very high $(\mathrm{V})$ & Montmorillonite \\
\hline
\end{tabular}

Fig. 6. Classification procedures for expansive soils based on the FSR (source: modified from Prakash \& Sridharan (2004).

Accordingly, the FSR and FSI can be related through FSR $=1+$ FSI (where FSI is in decimal value, not percentage). In addition to its reported superior performance in terms of predicting the degree of expansivity, the FSR provides additional information about the clay mineralogy of soils (see Fig. 6). Although the authors did not encounter negative FSI values for the soils investigated in their study, the contributors believe that compared with the FSI, the FSR would be a more suitable and meaningful model parameter, as it will produce a more generalised model capable of predicting the swelling pressure for a wider group of expansive soils. An upgraded swelling pressure model making use of the FSR could have the same functional form as that proposed in equation (6) of the original manuscript, but with the FSR in lieu of the FSI and employing recalibrated fitting parameters.
Correlations between FSI and fitting parameters $\alpha$ and $\beta$ The contributors agree that both fitting parameters $\alpha$ and $\beta$ will have a monotonically increasing trend with increasing the FSI. A key point, however, is the assumed linear relationships between these parameters and the FSI, as presented in equations (5a) and (5b) of the original manuscript - that is, making use of only two data points obtained from soils A and B to develop and validate a linear correlation between $\alpha$ or $\beta$ and the FSI (see Fig. 4 of the original manuscript). The contributors have sought to substantiate these linear correlations using the data for soils $\mathrm{C}$ and $\mathrm{D}$ given in Appendix A of the original manuscript; however, these datasets are not sufficiently large enough to be considered for validating, or possibly developing superior alternatives to, equations (5a) and (5b). Since publishing their paper, have the authors gathered new data that could be used for this purpose?

\section{Some other observations}

As a minor point noted in Table 1 of the original manuscript, the FSI for soils A, B, C and D has been reported to be $40 \cdot 8,10 \cdot 4,20 \cdot 0$ and $33.0 \%$, respectively. Making use of the FSI-based classification framework of Sridharan \& Prakash (2000), which has also been used by the authors, it would appear that these soils should all be classified as 'low' in terms of expansivity. However, from the same table, the corresponding classifications have been reported as very high, negligible, moderate and high, respectively. The contributors would appreciate some clarification on this apparent inconsistency. Currently, the assembled database seems to only cover/consider a narrow range of soil expansivity behaviour (i.e. low expansivity), and as such, may not be suitable for the development and validation of a generalised swelling pressure model.

\section{AUTHORS' REPLY}

The authors' paper proposed a novel formula to predict the swelling pressure of compacted expansive soils at a wide range of initial moisture contents and densities. One of the highlights of the formula is that the input parameters are easy to obtain. The input parameters used in the formula, as shown in equation (6) of the original manuscript, included initial dry density, variation of water content, $\Delta w=w_{\text {sat }}-$ $w_{\text {init }}$ and a soil expansivity indicator, named free swell index (FSI). The contributors raised several issues regarding the choice of FSI, its correlation with the LL and the derivation approach of the fitting parameters. The authors greatly appreciate the interest that has been taken in the paper, which should be a contribution to the current research of compacted expansive soils. The discussion provides evidence towards the importance of the determination of swelling pressure of clays in geotechnical applications of compacted expansive soils. The discussion and the reply, together with the original manuscript, should provide a better knowledge on the above subject. The following is a response to the points raised by the contributors.

\section{Mineralogy and FSI}

The contributors presented several issues regarding the proposed expansivity indicator, FSI. It should be clear, however, that the paper focuses on the formula development to predict the swelling pressure of compacted expansive soils. The authors believe that detailed discussion on the mineralogy and FSI is helpful but not essential due to the limitation of the length of the paper. 


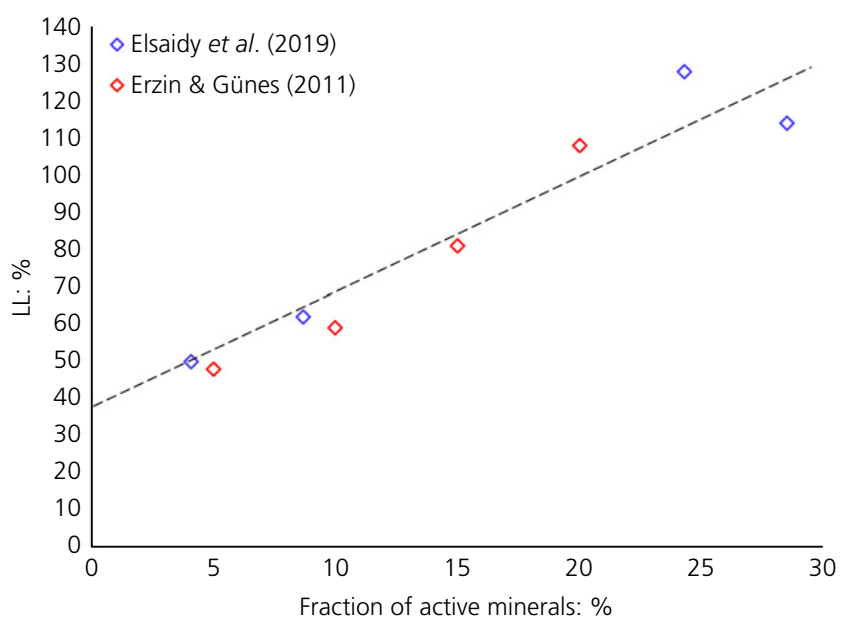

Fig. 7. Variations of LL against fraction of active minerals obtained from the literature and the original manuscript

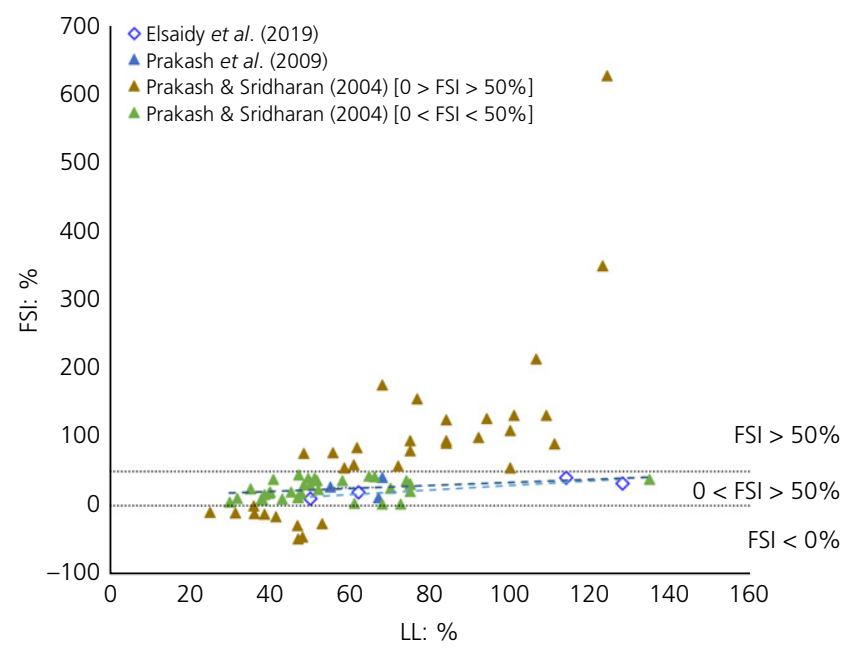

Fig. 8. Correlation between LL and FSI for soils of different expansivities derived from the literature and the discussion notes

The literature reveals the importance of including mineralogy (i.e. active minerals) in the swelling potential prediction formulas. This suggests that a parameter linked directly to the amount of active minerals in an expansive soil material would be important in the prediction formula. The contributors raised a valid point regarding a possible negative value of the FSI. Consequently, they proposed parameter of Sridharan \& Prakash (2000), named free swell ratio (FSR). The authors, however, did not experience any negative values within the specified range of FSI $<50 \%$. Furthermore, Prakash \& Sridharan (2004) validated the use of FSR as a clay mineralogy indicator using X-ray diffraction analysis. Accurate determination of the components of active minerals requires a quantitative method rather than a qualitative one (Srodon, 2002; Mitchell \& Soga, 2005; Srodon, 2006). Hence, the authors believe that a quantitative approach in the evaluation of the amount of active minerals would be a substantial complication as these techniques are not generally available in geotechnical laboratories; consequently the paper was limited to qualitative rather than quantitative approaches. In the authors' approach for quantifying active minerals, the combination of X-ray diffraction and X-ray fluorescence techniques was adopted, but we accept that this is unlikely in practice. The existence of smectite group (e.g. montmorillonite and vermiculite minerals) accounts for the swell-shrink behaviour of the clay materials when subject to wetting-drying (Mitchell \& Soga, 2005). Subsequently, the FSI was found directly related to the active minerals of the tested soils (refer to Fig. 1 of the original manuscript).

It is unfortunate that previous papers that deal with swelling potential formulas do not always include the FSI value. Due to this oversight, the authors needed to use another appropriate and available index (i.e. LL). Nevertheless, Fig. 7 supports that the LL is directly related to the amount of active minerals for the specific range of FSI $<50 \%$ in this study. Furthermore, the discussion ignored the fact that the current study focused only on compacted expansive soils having FSI $<50 \%$. Figure 8 includes same dataset used in the discussion and additional data from Prakash et al. (2009). It is well observed from the same figure that the trend of data points is quite similar, thus indicating that the LL is well correlated, only, with the $0<\mathrm{FSI}>50 \%$. Accordingly, it 's not appropriate to use the data published in Rao et al. (2004) who investigated soils having FSI $>100 \%$.

\section{General formula for swelling pressure}

In the discussion, the FSR (i.e. free swell ratio) was proposed to generate a formula for a wider range of expansivity. However, this is outside the scope of the current study. It should be mentioned that the authors experienced scattered results on using soils of different expansivity ranges in the validation process of the proposed formula.

\section{Fitting parameters of the proposed formula}

In the author's proposed formula, soils A and B were initially chosen to calibrate the fitting parameters. This choice judgement is based on covering the soil expansivity range in this study. In other words, soil A has the highest FSI value, whereas soil $\mathrm{B}$ holds the lowest value within the FSI $<50 \%$. On the basis of study results, the prediction formula predicts reasonably well swelling pressure of soils having expansivities within the FSI $>50 \%$ range and covering a wide range of initial soil conditions. Nevertheless, further research shows that there is still a shortage of tested soils having the same range of expansivity in the literature.

\section{Other observations}

Regarding Table 1 of the original manuscript, the authors aimed at showing the discrepancy of expansivity classification using various soil parameters. However, as mentioned in the discussion, it should be corrected that all the soils should be classified as 'low' based on FSI using Sridharan \& Prakash (2000).

\section{REFERENCES}

Elsaidy, H., Yan, W. M. \& Pender, M. J. (2019). A novel formula for the prediction of swelling pressure of compacted expansive soils. Géotech. Lett. 9, No. 3, 231-237, https://doi.org/10.1680/jgele. 18.00203

Erzin, Y. \& Güneş, N. (2011). The prediction of swell percent and swell pressure by using neural networks. Math. Comput. Appl. 16, No. 2, 425-436.

Mitchell, J. K. \& Soga, K. (2005). Fundamentals of soil behavior, 3rd edn. New York, NY, USA: John Wiley \& Sons.

Nagaraj, H. B. \& Suresh, M. R. (2019). Absorption limit of kaolinitic and montmorillonitic soils. Geomech. Geoeng. (in press), https://doi.org/10.1080/17486025.2019.1680881. 
Prakash, K. \& Sridharan, A. (2004). Free swell ratio and clay mineralogy of fine-grained soils. Geotech. Test. J. 27, No. 2, 220-225, https://doi.org/10.1520/gtj10860.

Prakash, K., Sridharan, A., Prasanna, H. S. \& Manjunatha, K. (2009). Identification of soil clay mineralogy by free swell ratio method. In Proceedings of the Indian geotechnical conference, Guntur, India. Chennai, India: Allied Publishers Pvt. Ltd. pp. 27-30.

Rao, A. S., Phanikumar, B. R. \& Sharma, R. S. (2004). Prediction of swelling characteristics of remoulded and compacted expansive soils using free swell index. Q. J. Eng. Geol. Hydrogeol. 37, No. 3, 217-226, https://doi.org/10.1144/1470-9236/03-052.

Sridharan, A. \& Prakash, K. (1999). Mechanisms controlling the undrained shear strength behaviour of clays.
Can. Geotech. J. 36, No. 6, 1030-1038, https://doi.org/10. 1139/t99-071.

Sridharan, A. \& Prakash, K. (2000). Classification procedures for expansive soils. Proc. Inst. Civ. Engrs - Geotech. Engn. 143, No. 4, 235-240, https://doi.org/10.1680/geng.2000.143.4.235.

Sridharan, A., Rao, S. M. \& Murthy, N. S. (1985). Free swell index of soils; a need for redefinition. Indian Geotech. J. 15, No. 2, 94-99.

Środoń, J. (2002). Quantitative mineralogy of sedimentary rocks with emphasis on clays and with applications to $\mathrm{K}$-Ar dating. Mineral. Mag. 66, No. 5, 677-687, https://doi.org/10.1016/ S1572-4352(05)01028-7.

Środoń, J. (2006). Identification and quantitative analysis of clay minerals. Dev. Clay Sci. 1, 765-787. 